\title{
O PRINCÍPIO DO ACESSO À JUSTIÇA E O INCIDENTE DE COLETIVIZAÇÃO DE DEMANDAS REPETITIVAS
}

\author{
Rodrigo Brunieri Castilho ${ }^{1}$ \\ Silvia Mattei $^{2}$
}

CASTILHO, R. B.; MATTEI, S. O princípio do acesso à justiça e o incidente de coletivização de demandas repetitivas. Rev. Ciênc. Juríd. Soc. UNIPAR. Umuarama. v. 17, n. 1, p. 43-51, jan./jun. 2014.

RESUMO: Durante o trâmite do Anteprojeto do Novo CPC no Congresso Nacional foi introduzido o Incidente de Resolução de Demandas Repetitivas, que tem por escopo o proferimento de um julgamento único para os processos que possuem o mesmo fundamento fático e jurídico. Esse incidente é de inspiração alemã e se apoia na ideia da celeridade da justiça sem que se negue o acesso à justiça.

PALAVRAS-CHAVE: Novo CPC; Incidente de Resolução de Demandas Repetitivas; Celeridade da justiça; Acesso a justiça.

\section{INTRODUÇÃO}

Segundo Cândido Rangel Dinamarco (2002), a efetividade do processo se mede pela sua aptidão para "cumprir integralmente toda a sua função sociopolítico-jurídica, atingindo em toda a plenitude todos os seus escopos institucionais".

Humberto Theodoro Junior (2013) analisa que toda uma grande reforma que se fez nos últimos anos, nos textos do Código de Processo Civil, fora com o confessado propósito de desburocratizar o procedimento e acelerar o resultado da prestação jurisdicional. E ainda completa dizendo que esse movimento reformador não é fenômeno isolado do processo brasileiro. Todo o mundo ocidental de raízes romanísticas tem procurado modernizar o ordenamento positivo processual seguindo orientação mais ou menos similar, cuja preocupação dominante é a de superar a visão liberal herdada do século XIX, excessivamente individualista e pouco atenta ao resultado pratico da resposta jurisdicional.

De fato, diferentemente do forte individualismo que marcou o Estado liberal, muitos dos desafios presentes impostos ao Direito e ao Poder Judiciário hoje, têm uma lógica distinta. A proteção socioambiental, a garantia da sócio-

DOI: https://doi.org/10.25110/rcjs.v17i1.2014.5354

${ }^{1}$ Acadêmico PIC/UNIPAR

${ }^{2}$ Docente Orientadora PIC/UNIPAR 
diversidade e da biodiversidade, a proteção dos direitos de grupos específicos como consumidores, idosos, homossexuais, transcendem a esfera individual e se voltam à proteção de interesses de classes e grupos, ou à proteção de bens coletivos que, na ausência de mecanismos adequados e satisfatórios, acabam se transformando em demandas repetitivas ${ }^{3}$.

\section{DO INCIDENTE DE RESOLUÇÃO DE DEMANDAS REPETITIVAS NO PLS 166/2010}

Para uma melhor explanação sobre o tema, faz se necessário conceituar demanda repetitiva: Assim, demandas repetitivas são aquelas que possuem origem comum ou o mesmo fundamento legal invocado.

Diante da conceituação, podemos dizer que hoje uma das maiores causas do esgotamento do Judiciário brasileiro ${ }^{4}$ justamente tem sido o enorme volume de ações repetitivas, que reproduzem litígios calcados em fatos e fundamentos idênticos.

O projeto de Lei $n^{\circ} 166 / 2010$, que em seu texto trouxe uma inovação ao abordar especificadamente nos artigos 930 a 941, o Incidente de Resolução de Demandas Repetitivas, teve sua inspiração no modelo de tutela coletiva alemã, para eles, procedimento-modelo do mercado de capitais, chamado de Musterverfahren.

Importante tecer breves comentários acerca deste instituto, tendo em vista que o estudo do direito comparado serve para melhor compreendermos o nosso ordenamento. Salienta-se que a Alemanha não tem grandes experiências legislativas no que tange a tutela dos processos coletivos, diferentemente do direito estadunidense, razão pela qual a doutrina consultada, praticamente de forma uníssona, entende que o instituto das demandas repetitivas deve ser aperfeiçoado através da experiência norte americana (MARINONI, 2010).

O sistema alemão, Musterverfahren, foi instituído para conferir celeridade aos julgamentosque estavam paralisados devido ao imenso número de ações que ingressaram no tribunal de Frankfurt, sede da bolsa de valores; as demandas repetidas versavam sobre o mercado de capitais, mais especificamente um problema que ocasionou o declínio do valor nominal de determinadas ações de uma empresa, gerando uma massificação de demandas e aglomeração no tribunal (ROSSONI, 2013).

\footnotetext{
${ }^{3}$ Demandas repetitivas relativas ao sistema de crédito no brasil e propostas para sua solução.Disponível em: http://www.cnj.jus.br/images/pesquisas- judiciarias/Publicacoes/relat_pesquisa_pucpr_edital1_2009.pdf. Acesso em: 25 de nov. de 2013

${ }^{4}$ Conforme pesquisa CNJ. Disponível em: http://www.cnj.jus.br/images/pesquisas-judiciarias/pesquisa_100_maiores_litigantes.pdf. Acesso em: 25 de nov. de 2013
} 
Com intuito de não causar maiores transtornos, na medida em que houve concomitante ingresso de mais de treze mil ações, o que ocasionou a total paralisação da seção de direito comercial, foi instituído o Musterverfahren.Assim, o direito alemão por meio do julgamento de uma causa piloto, igual à proposta doIncidente, encontrou a solução para esta imensurável demanda que batia a sua porta.

OMusterverfahren possui trêsfases distintas entre si:

I) Admissibilidade perante o juiz de primeiro grau;

II) Julgamento da questãocomum de fato ou direito pelo Tribunal;

III) Definição da questão individual (CAPONI, 2013 apud ROSSONI, 2013).

Durante a tramitação do Processo- Modelo qualquer interessado pode intervir, a fim de opinar para a solução dada pelo tribunal a matéria, da mesma forma que prevê o incidente.

Diferentemente do modelo proposto pelo NCPC o procedimento alemão distribui as custas processuais entre as partes; de acordo com ROSSONI (2013): os custos são proporcionalmente computados como despesas do processo de origem, devendo as cotas-parte serem calculadas comparando a grandeza das pretensões individuais com o total das exigências paralelas das partes e intervenientes"

Foi neste sistema que a Comissão responsável pela elaboração do anteprojeto do NCPC buscou inspiração para o ora estudado Incidente de Resolução de Demandas Repetitivas; o Musterverfahrené um procedimento experimental e teve vigência até primeiro de outubro de 2012, após, seria feito uma análise da sua trajetória.

O Incidente de Resolução Demandas Repetitivas proposto no NCPC, tem o objetivo de tutelar os direitos da coletividade, que se mesclam cada vez mais, mediante o dinamismo trazido pela constante evolução social-democrática, da mesma forma, também foi criado para fins de agregar segurança jurídica aos julgamentos que envolvam a mesma matéria. Em sua previsão no PLS 166/2010, precisamente nos arts. 930 a 941, trata-se de um instituto cabível em situações onde, decorrente de demandas em andamento, for detectada controvérsia que na exata dicção do texto do art. 930, possui potencial de gerar relevante multiplicação de processos fundados em idêntica questão de direito (portanto não cabe às questões de fato) e, além disso, de causar grave insegurança jurídica, decorrente de decisões conflitantes.

Os requisitos de admissibilidade do Incidente de Resolução de Demandas Repetitivas podem ser assim apontados:

1) A identificação de controvérsia com potencial de gerar relevante multiplicação de processos fundados em idêntica questão de direito e de causar grave 
insegurança jurídica decorrente do risco de coexistência de decisões conflitantes.

2) A legitimidade para o pedido de instauração do incidente. (Magistrado, partes, Ministério Público, Defensoria Pública).

3) A instrução com os documentos necessários à demonstração da necessidade de instauração do incidente, logicamente, fundamentado na circunstância comprobatória da existência de "controvérsia com potencial de gerar relevante multiplicação de processos fundados em idêntica questão de direito e de causar grave insegurança jurídica, decorrente do risco de coexistência de decisões conflitantes".

Resumidamente, sendo rejeitado o IRDR, retoma-se a ação originária, caso contrário, o tribunal suspenderá todas as ações pendentes tanto em primeiro quanto em segundo grau (art. 934 do PLS 166/2010), cabendo assinalar que, a despeito da aludida suspensão de ações pendentes, havendo necessidade de adoção de medidas de urgência no âmbito de tais demandas, autoriza o paragrafo único do art. 934 do PLS 166/2010 que estas possam ser praticadas. Uma vez julgando a questão de direito submetida, o tribunal competente (por órgão colegiado) lavrará acórdão respectivo, cujo teor (tese jurídica) será vinculante e imposta a todos os juízes ou órgãos fracionários no âmbito de sua competência (art. $933, \S 2^{\circ}$ ).

\section{DO ACESSO À JUSTIÇA}

Quando da apresentação do anteprojeto do NCPC ao Senado Federal (BRASIL, 2010), indicou-se um novo código "que privilegiasse a simplicidade da linguagem e ação processual, a celeridade do processo e a efetividade do resultado da ação, além do estímulo à inovação e a modernização do procedimento, garantindo o respeito ao devido processo legal”.

O princípio do due process of law como postulado constitucional fundamental do processo civil, é indicado por Nelson Nery Junior (2010, P. 7879) como base sobre o qual todos os outros princípios e regras se sustentam. A Constituição Federal Brasileira de 1988 fala expressamente que "ninguém será privado da liberdade ou de seus direitos sem o devido processo legal" (Art. $5^{\circ}$, LIV, CF).

Nesta esteira, não se pode falar em acesso à justiça sem citar Cappelletti e Garth, ainda mais quando falamos do Incidente de Resolução de Demandas Repetitivas, que envolve os interesses difusos, tema que faz parte da segunda onda reformista, pelos respectivos autores propostos, em prol do acesso mais igualitárioe operante da justiça. Para os doutrinadores, inserir um mecanismo de resolução de demandascoletivas dentro do Código de Processo Civil: 
É sem dúvida uma verdadeira "revolução" que está se desenvolvendo dentro do processo civil, ... A concepção tradicional do processo civil não deixa espaço para a proteção dos direitos difusos. O processo era visto apenas como um assunto entre duas partes, que se destinava à solução de uma controvérsia entre estas mesmas partes a respeito de seus próprios interesses individuais. Direitos que pertencem a um grupo, ao público em geral... (CAPPELLETTI; GARTH; NORTHFLEET, 2008, p. 49).

Dessa maneira, o IRDR, deriva da análise dos problemas que o direito material moderno traz para o processo, pois este possui autonomia legitimada pela existência de normas e princípios processuais que visam à aplicação equânime do direito material envolvido.

Nesse pensamento, a noção clássica de demanda, cuja linearidade era adequada à causa direta entre dois indivíduos, pelo IRDR temos o nascimento de relações processuais que comportam uns sem número de sujeitos processuais.

Para melhor pontuar o princípio do acesso à justiça, faz-se necessário analisar que o IRDR distingue-se dos direitos coletivos (porque nesses a titularidade são de um grupo, categoria, classe, reunida em torno de uma relação jurídica), e também dos direitos difusos (pois, que mesmo que há um direito de titularidade indeterminada, o aspecto coletivo do IRDR advém de uma ligação fática entre os membros do grupo de litigantes), ou seja, o IRDR provém de direitos que embora sejam oriundos de um prejuízo individualizado, são causados por um fator de origem comum, assemelhando-se então aos direitos individuais homogêneos, onde pela reunião das ações propostas individualmente, temos a consequência da maior eficiência e do equilíbrio processual na relação imposta ao judiciário (LÉVY, 2011).

Neste contexto do principio do acesso à justiça, podemos assim analisar:

1) Possibilidade de ingressar em juízo mesmo sendo um pequeno e pouco usual litigante;

2) Diminuição e repartição do custo processual, que na maioria das vezes são dispendiosos;

3) Maior equilíbrio da relação processual, aumentando-se o poder da parte lesada quando associada com outros indivíduos na mesma situação, facilitando uma justa repartição dos ônus processuais, e;

4) A análise mais técnica do caso, com a participação de órgãos especializados, como amicus curiae, sem maiores custos.

Além do acesso à justiça, outros princípios podem ainda serem apontados, entre eles:

1) Celeridade Processual: considerando que os processos serão decidi- 
dos conjuntamente, e a atenuação da hipertrofia de carga de trabalho do judiciário brasileiro.

2) Segurança Jurídica: pois, por haver posicionamentos diferentes e incompatíveis nos tribunais, a respeito da mesma norma jurídica, leva jurisdicionados que estejam em situações idênticas submeter-se a regras diferentes. Assim, afastam-se decisões contraditórias.

A exposição de motivos do NCPC ao Senado Federal, traz uma importante questão, que vale a pena transcrever para elucidar tais princípios: “... sua finalidade está de acordo com o cerne da reforma proposta... o incidente foi justamente criado para evitar a dispersão excessiva da jurisprudência e atenuar assoberbamento de trabalhodo Poder Judiciário...” (BRASIL, 2010).

Lenio Luiz Streck (2013), em recente artigo para o CONJUR, analisando coerência, integridade e estabilidade da jurisprudência, explica "que haverá coerência se os mesmos princípios hermenêuticos forem aplicados a decisões para casos idênticos, assegurando a integridade do direito a partir da força normativa da constituição".

Dessa forma, o que se pode constatar é a criação de um instituto que carrega em si um mecanismo para auferir maior segurança jurídica, valor intrínseco ao Estado Democrático de Direito, aos julgamentos.

\section{CONCLUSÃO}

Bedaque (2009) destaca que a ciência processual brasileira encontra-se em evolução, daí a conscientização que a importância do processo está em seus resultados. O IRDR proposto no NCPC age com a finalidade de conferir racionalidade e uniformidade na obtenção de julgados, que, por tais regras agilizam o resultado, evitam a divergência jurisprudencial - que conferem maior isonomia entre as pessoas - permite um alargamento do acesso à justiça e evitam o congestionamento das vias judiciais.

Em que pese as críticas sobre o enfraquecimento do juízo "a quo", e com amaior possibilidade de influência e controle político da decisão, uma vez que as Cortes superiores podem ser mais propensas a decisões políticas, um importante passo foi dado, e é importante referir que quando se fala em direito coletivo nacional não temos nada parecido, e, já é tempo de acompanharmos as mudanças que vem ocorrendo no direito comparado. Julgar conjuntamente a mesma matéria irá desafogar o judiciário concedendo celeridade para a tramitação de outros inúmeros processos, o que de fato espelhará em todo o sistema jurídico, além de garantir aos jurisdicionados a segurança jurídica, pressuposto inerente e esperado quando falamos em Estado de Direito. Vantagens sejam vistas, então, advindas do controle concentrado, especialmente com respeito à segurança jurí- 
dica e, em certa medida, à diminuição da morosidade processual nos tribunais.

Assim visto, que o estudo comparado acerca do IRDR nos possa servir a evitar um importantíssimo desatento das peculiaridades atuais do direito brasileiro, primando pela adaptação dos institutos alienígenas à nossa realidade, sob pena, de nos tonarmos, nas palavras de Sergio Buarque de Holanda (2002): "desterrados em nossas terras".

\section{REFERÊNCIAS}

BRASIL. Congresso Nacional. Senado Federal. Código de processo civil: anteprojeto / Comissão de Juristas Responsável pela Elaboração de Anteprojeto de código de processo civil. Brasília: Senado Federal, 2010. Disponível em: $<\mathrm{http}$ //www.senado.gov.br/senado/novocpc/pdf/Anteprojeto.pdf $>$. Acesso em: 24 nov. 2013.

CAPPELlETti, M.; GARTH, B.; NORTHFLEET, E. G. Acesso à justiça. Porto Alegre: Fabris, 2008. p. 49.

CAPONI; R. Modellieuropeidi tutela collettivanel processo civile: esperienzatedesca e italiana a confronto. Rivistra trimestrale di diritto e procedura civile. Milano: Giuffrè, 2007. v. 4. p. 1230. IN. ROSSONI, Igor Bimkowski . "Incidente de Resolução de Demandas Repetitivas" e a Introdução do GroupLitigation no Direito Brasileiro: Avanço ou Retrocesso? Disponível em: http://www.tex.pro.br/home/noticias2/44-artigos-dez-2010/4740-oincidente-de-resolucao-de-demandas-repetitivas-e-a-introducao-do-grouplitigation-no-direito-brasileiro-avanco-ou-retrocesso. Acesso em: 24 nov. 2013.

DINAMARCO, C. R. A instrumentalidade do processo. 10. ed. São Paulo: Malheiros, 2002. p. 330. IN. AMARAL, G. R. Efetividade, segurança, massificação e a proposta de um incidente de resolução de demandas repetitivas. Revista do Processo, v. 196, p. 237-275, São Paulo: Revista dos Tribunais, jun. 2011.

DEMANDAS repetitivas relativas ao sistema de crédito no Brasil e propostas para sua solução. Disponível em: <http://www.cnj.jus.br/images/pesquisasjudiciarias/Publicacoes/relat_pesquisa_pucpr_edital1_2009.pdf $>$. Acesso em: 25 nov. 2013.

HOLANDA, S. B. Raízes do Brasil. Companhia das Letras, 2002. p. 31. IN. LÉVY, Daniel de Andrade. O incidente de resolução de Demandas repetitivas 
no Anteprojeto do Novo Código de Processo Civil - Exame à luz da Group Litigation Order Britânica. Revista do Processo, v. 196, p. 165-206, São Paulo: Revista dos Tribunais, jun. 2011.

LÉVY, D. de A. O incidente de resolução de demandas repetitivas no anteprojeto do novo código de processo civil: Exame à luz da Group Litigation Order Britânica. Revista do Processo, São Paulo: Revista dos Tribunais, v. 196, p. 165-206, jun. 2011.

MARINONI, L. G.; MITIDIERO, D. F. O projeto do CPC: críticas e propostas. São Paulo: Editora dos Tribunais, 2010. p. 178.

NERY JUNIOR, N. Princípios do processo na Constituição Federal. Revista dos Tribunais v. 10, 2010. p.78-79.

PESQUISA CNJ 100 maiores litigantes. Disponível em: <http://www.cnj.jus. br/images/pesquisas-judiciarias/pesquisa_100_maiores_litigantes.pdf $>$. Acesso em: 25 nov. 2013.

ROSSONI, I. B. Incidente de resolução de demandas repetitivas" e a introdução do GroupLitigation no direito brasileiro: avanço ou retrocesso? Disponível em: $<$ http://www.tex.pro.br/home/noticias2/44-artigos-dez-2010/4740-o-incidentede-resolucao-de-demandas-repetitivas-e-a-introducao-do-group-litigation-nodireito-brasileiro-avanco-ou-retrocesso>. Acesso em: 24 nov. 2013.

\section{STRECK, L. L. Por que agora dá para apostar no projeto do novo CPC!} Disponível em: <http://www.conjur.com.br/2013-out-21/lenio-streck-agoraapostar-projeto-cpc $>$. Acesso em: 25 nov. 2013.

THEODORO JÚNIOR, H. Curso de direito processual civil: teoria geral do direito processual civil e processo de conhecimento. 54. ed. Rio de Janeiro: Forense, 2013. p. 5 - 6.

\section{THE PRINCIPLE OF ACCESS TO JUSTICE AND THE INCIDENT OF COLLECTIVIZATION OF REPETITIVE DEMANDS}

ABSTRACT: During the processing of the New CPC Draft, the National Congress was introduced to the Repetitive Demand Resolution Incident, with the scope of reaching a single trial for the processes that have the same factual and legal basis. This incident has a German inspiration and is based on the idea of justice celerity without denying access to justice. 
KEYWORDS: New CPC; Repetitive Demand Resolution Incident; Justice Celerity; Access to Justice.

\section{EL PRINCIPIO DEL ACCESO A LA JUSTICIA Y EL INCIDENTE DE COLECTIVIZACIÓN DE DEMANDAS REPETITIVAS}

RESUMEN: Durante el trámite del Anteproyecto del Nuevo CPC en el Congreso Nacional se ha introducido el Incidente de Resolución de Demandas Repetitivas, que tiene alcance la pronunciación de un juzgado único para los procesos que tienen el mismo fundamento fático y jurídico. Ese incidente es de inspiración alemana y se apoya en la idea de la celeridad de la justicia, sin que se niegue el acceso a la justicia.

PALABRAS CLAVE: Nuevo CPC; Incidente de Resolución de Demandas Repetitivas; Celeridad de la justicia; Acceso a la justicia. 